\title{
Peripherally Acting $\mu$-Opioid Receptor Antagonists in the Management of Postoperative lleus: a Clinical Review
}

\author{
Karim Chamie ${ }^{1} \cdot$ Vishnukamal Golla $^{1} \cdot$ Andrew T. Lenis ${ }^{1} \cdot$ Patrick M. Lec $^{1} \cdot$ Siamak Rahman $^{2} \cdot$ Eugene R. Viscusi $^{3}$
}

Received: 24 January 2020 / Accepted: 25 May 2020 / Published online: 10 August 2020

(C) 2020 The Author(s)

\begin{abstract}
Postoperative ileus (POI) and constipation are common secondary effects of opioids and carry significant clinical and economic impacts. $\mu$-Opioid receptors mediate opioid analgesia in the central nervous system (CNS) and gastrointestinal-related effects in the periphery. Peripherally acting $\mu$-opioid receptor antagonists (PAMORAs) block the peripheral effects of opioids in the gastrointestinal tract, while maintaining opioid analgesia in the CNS. While most are not approved for POI or postoperative opioid-induced constipation (OIC), PAMORAs have a potential role in these settings via their selective effects on the $\mu$-opioid receptor. This review will discuss recent clinical trials evaluating the safety and efficacy of PAMORAs, with a focus on alvimopan $\left(\right.$ Entereg $^{\circledR}$ ) and methylnaltrexone $\left(\right.$ Relistor $\left.^{\circledR}\right)$ in patients with POI or postoperative OIC. We will characterize potential factors that may have impacted the efficacy observed in phase 3 trials and discuss future directions for the management and treatment of POI.
\end{abstract}

Keywords Postoperative ileus · Opioid-induced constipation · Opioid analgesics $\cdot \mu$-Receptor antagonists $\cdot$ Alvimopan · Methylnaltrexone

\section{Introduction}

\section{Postoperative lleus}

Postoperative ileus (POI) is defined as a delay of normal gastrointestinal (GI) motility after surgery and can be secondary to surgical stress responses (i.e., bowel manipulation and/or resection), neurohormonal dysfunction, inflammation, fluid and electrolyte imbalances, and opioids (both endogenous and exogenous). ${ }^{1-3}$ Clinical features of POI include bloating, abdominal distention, nausea, vomiting, delay in oral intake, and pain. ${ }^{4}$ The incidence of POI has been reported in 10 to $30 \%$ of patients who have undergone colectomy,

Eugene R. Viscusi

Eugene.Viscusi@jefferson.edu

1 Department of Urology, University of California Los Angeles Medical Center, Los Angeles, CA, USA

2 Department of Anesthesiology, University of California Los Angeles Medical Center, Los Angeles, CA, USA

3 Department of Anesthesiology, Sidney Kimmel Medical College at Thomas Jefferson University, 111 S 11th St, Ste G-8290, Philadelphia, PA 19107, USA cholecystectomy, or other abdominal surgeries. ${ }^{1,5}$ Multiple factors may affect the incidence of POI, including the type and duration of surgery, ${ }^{6,7}$ inflammatory factors induced during surgery, ${ }^{8}$ and opioid dose $e^{5}$ and duration. ${ }^{9}$

POI is associated with decreased patient satisfaction, extended hospital length of stay, medical complications, increased hospital costs, subsequent surgical interventions, and higher readmission rates. ${ }^{5,10,11}$ Hospital costs in patients with POI are estimated to be double compared with those who have normal return of bowel function (median total hospital costs, $\$ 21,046$ vs $\$ 10,945){ }^{5}$ As such, accelerating GI recovery after surgery is paramount in improving patient outcomes and decreasing costs.

Strategies to improve rates of POI have changed overtime. Traditional approaches to POI prevention include chewing gum, adequate fluid resuscitation, and administration of prokinetic drugs and laxatives. ${ }^{3}$ However, some of these measures are associated with additional risks or have limited or unproven efficacy. ${ }^{3}$ More contemporary multimodal strategies, termed enhanced recovery after surgery (ERAS) protocols, aim to limit the stress response to surgery. ${ }^{3}$ Examples of key interventions of the ERAS protocol are to encourage ambulation, early diet, and multimodal analgesia. ${ }^{3,12-15}$ Peripheral $\mu$-opioid receptor 
antagonists (PAMORAs) also play a critical role in many ERAS protocols, especially among patients undergoing open surgery. ${ }^{3}$ Herein, we review the role of $\mu$-opioid receptors in GI motility, the use of PAMORAs after surgery to accelerate GI recovery, and discuss future directions.

\section{Peripherally Acting $\mu$-Opioid Receptor Antagonists in GI Recovery}

Opioid analgesics are often administered during and after surgical procedures for the management of intraoperative and postoperative pain, respectively. ${ }^{16}$ In addition to their intended central effect on pain receptors, opioids have an undesired influence peripherally in the GI tract, including decreased gastric motility and emptying, inhibited bowel propulsion, and altered fluid and electrolyte balance. ${ }^{17}$ Opioids profoundly affect the forward propulsive and coordinated peristaltic activity of the bowel leading to both POI and postoperative opioid-induced constipation (OIC). ${ }^{16,}{ }^{18}$ Although OIC and POI are similar, POI involves the loss of forward propulsive motion of the GI tract after surgery. ${ }^{19}$

Opioid receptors, of which there are 3 main classes $(\mu, \delta$, $\kappa)$, are ubiquitous in the central nervous system (CNS) and enteric nervous system. ${ }^{17}$ Nonselective $\mu$-opioid receptor antagonists cross the blood-brain barrier and target both central and peripheral $\mu$-opioid receptors. ${ }^{20,}{ }^{21}$ For example, the nonselective $\mu$-opioid receptor antagonist naloxone $\left(\operatorname{Narcan}^{\circledR}\right)$ has a long clinical history of successful use for the treatment of opioid overdose, reversing overdose-induced respiratory depression while reducing symptoms of acute withdrawal in opioid-dependent patients. ${ }^{22}$ Targeting of both central and peripheral $\mu$-opioid receptors relieves constipation but also reverses opioid analgesia. ${ }^{20,21}$

PAMORAs aim to mitigate the risk of POI while maintaining analgesia in patients receiving postoperative opioids by selectively inhibiting peripheral $\mu$-opioid receptors. ${ }^{23}$ The effects of PAMORAs are limited to the periphery given their polarity, large structure, and low lipid solubility that prevents them from crossing the blood-brain barrier. ${ }^{24}$ As such, selective antagonism of the GI $\mu$-opioid receptors blocks the peripheral effects of opioids, while maintaining the analgesic effects of opioids in the CNS. ${ }^{23,} 25$

Most of the approved PAMORAs are not indicated for POI or postoperative OIC, but they may have a role in the management of postoperative bowel dysfunction by virtue of their abovementioned mechanism of action. ${ }^{19}$ Currently, alvimopan and methylnaltrexone have the most significant data supporting their use for POI. Other PAMORAs, such as naloxegol, are less thoroughly studied with only small series demonstrating some efficacy for POI. ${ }^{26}$

\section{PAMORAs for POI}

\section{Alvimopan (Entereg ${ }^{\circledast}$ )}

Alvimopan is the only PAMORA indicated to accelerate the time to upper and lower GI recovery following partial bowel resection surgery with primary anastomosis (Table 1). ${ }^{27}$ It is limited to 15 total doses, which can only be administered in the hospital. ${ }^{27}$ Dosing guidelines recommend one 12-mg capsule $30 \mathrm{~min}$ to $5 \mathrm{~h}$ before surgery and one 12-mg capsule twice daily beginning the day after surgery until discharge for a maximum of 7 days. ${ }^{27}$ In clinical studies for the management of POI, alvimopan was administered orally (alvimopan 6 and/ or $12 \mathrm{mg}$ ) preoperatively and continued following surgery. ${ }^{28-33}$

\section{Alvimopan and GI Recovery}

The safety and efficacy of alvimopan has been evaluated in patients undergoing major abdominal surgery, including bowel resection, ${ }^{28-32}$ hysterectomy, ${ }^{30,31,33}$ and radical cystectomy. ${ }^{34}$ The primary efficacy endpoint for the earlier alvimopan efficacy studies was time to recovery of GI function as demonstrated by the endpoint GI3. ${ }^{29}, 31,32$ GI3 is a composite endpoint determined by the time that a patient first tolerated solid food (a marker for upper gastrointestinal function recovery) and the time that a patient first passed either flatus or had a bowel movement (a marker for lower gastrointestinal recovery). ${ }^{29-32}$ However, the GI3 endpoint did not demonstrate statistically significant differences compared with placebo in every alvimopan study (Table 2). ${ }^{29,31,33}$ Post hoc analysis of the data suggested that a secondary endpoint, GI2, was more objective. The GI2 endpoint is the same as the GI3 endpoint but eliminates flatus as a marker for lower GI recovery. Flatus has been found to be subjective and highly variable. ${ }^{29-32}$ As such, GI2 was preferentially utilized in subsequent alvimopan studies. ${ }^{28,29,32,33}$ Indeed, across most studies, time to the GI2 endpoint, regardless of whether it was a primary or secondary endpoint, was reduced in the alvimopan group compared with that in the placebo group. ${ }^{28,}$ 29, 33 Overall, alvimopan shortened the time to GI recovery and time to readiness for discharge (Table 2). ${ }^{28,} 30,32,35$

\section{Alvimopan and Hospitalization}

The effect of alvimopan has also been studied in large databases in order to evaluate the effects on length of stay and postoperative complications. For example, the Premier Perspective database is an observational propensity-matched cohort study that includes hospitalized postsurgical patients from a network of more than 400 hospitals. ${ }^{36}$ Using this database, Steele and colleagues evaluated the effect of alvimopan on clinical outcomes and healthcare utilization in 
Table 1 Summary of alvimopan and methylnaltrexone use $\mathrm{e}^{27,40}$

\begin{tabular}{|c|c|c|c|c|}
\hline Drug & Indications and usage & $\begin{array}{l}\text { Route of } \\
\text { administration }\end{array}$ & Dosing & Safety \\
\hline $\begin{array}{l}\text { Alvimopan } \\
\left.\text { (Entereg }^{\circledR}\right)\end{array}$ & $\begin{array}{l}\text { Indicated to accelerate the time to upper } \\
\text { and lower GI recovery following } \\
\text { surgeries that include partial bowel } \\
\text { resection with primary anastomosis } \\
\text { REMS for short-term use }\end{array}$ & Oral & $\begin{array}{l}\text { Preoperative and } \\
\text { postoperative } \\
\text { - } 12 \mathrm{mg}, 30 \mathrm{~min} \text { to } 5 \mathrm{~h} \\
\text { before surgery followed } \\
\text { by } 12 \mathrm{mg} \text { BID after } \\
\text { surgery for up to } 7 \text { days } \\
\text { In-hospital administration } \\
\text { only } \\
\text { - Maximum of } 15 \\
\text { in-hospital doses }\end{array}$ & $\begin{array}{l}\text { - Includes a boxed warning and REMS for } \\
\text { short-term use because of the potential } \\
\text { risk of MI with long-term use } \\
\text { - Previous opioid exposure increases } \\
\text { sensitivity } \\
\text { - Not recommended in patients with severe } \\
\text { hepatic impairment, end-stage renal } \\
\text { disease, complete GI obstruction, surgi- } \\
\text { cal correction of complete bowel } \\
\text { obstruction, pancreatic or gastric anas- } \\
\text { tomosis }\end{array}$ \\
\hline $\begin{array}{l}\text { Methylnaltrexone } \\
\quad\left(\text { Relistor }^{\circledR}\right)\end{array}$ & $\begin{array}{l}\text { Not indicated for OIC in the surgical } \\
\text { setting or POI } \\
\text { Indicated for treatment of OIC in adults } \\
\text { with: } \\
\text { - Chronic noncancer pain, including } \\
\text { patients with chronic pain related to } \\
\text { prior cancer or its treatment who do not } \\
\text { require frequent opioid dosage } \\
\text { escalation (injection and tablets) } \\
\text { - Advanced illness or pain caused by } \\
\text { active cancer who require opioid } \\
\text { dosage escalation for palliative care } \\
\text { (injection) }\end{array}$ & $\begin{array}{r}\text { Oral or SC } \\
\text { injection }\end{array}$ & $\begin{array}{l}\text { For OIC in adult patients } \\
\text { with chronic noncancer } \\
\text { pain: } \\
\text { - } 450 \mathrm{mg} \text { per oral QD } \\
\text { - } 12 \mathrm{mg} \text { SC QD } \\
\text { For OIC in adult patients } \\
\text { with advanced illness: } \\
\text { - One SC dose EOD, as } \\
\text { needed according to } \\
\text { weight }\end{array}$ & $\begin{array}{l}\text { - Not recommended in patients with } \\
\text { known or suspected GI obstruction and } \\
\text { at an increased risk of recurrent } \\
\text { obstruction } \\
\text { - May cause severe or persistent diarrhea } \\
\text { - May result in symptoms of opioid } \\
\text { withdrawal }\end{array}$ \\
\hline
\end{tabular}

$B I D$ twice daily, $E O D$ every other day, $G I$ gastrointestinal, $M I$ myocardial infarction, $O I C$ opioid-induced constipation, $P O I$ postoperative ileus, $Q D$ once daily, REMS risk evaluation and mitigation strategy, $S C$ subcutaneous

patients undergoing bowel resection. ${ }^{36}$ Compared with matched cohorts $(n=18,559)$, patients receiving alvimopan $(n=18,559)$ had significantly reduced postoperative length of stay (mean \pm standard deviation, $4.62 \pm 2.45$ days vs $5.24 \pm$ 3.35 days; $P<0.001$ ). ${ }^{36}$ In addition, alvimopan was associated with significantly reduced postoperative GI complications, urinary tract infections, and postoperative infections (all $P<$ 0.001). ${ }^{36}$ Cardiovascular, pulmonary, and thromboembolic events were also significantly reduced in the alvimopan group when compared with those in matched controls $(P<0.001){ }^{36}$ The authors noted that these improved outcomes may have been a result of shorter hospital length of stays and the implementation of ERAS protocols. ${ }^{36}$

In a recent subanalysis of patients who underwent bowel resection from the Premier Perspective database, alvimopan ( $n$ $=15,719)$ reduced the incidence of POI $(P<0.001)$, POIrelated readmission $(P<0.01)$, and length of hospital stay $(P$ $<0.001)$ compared with matched controls $(n=37,229) .{ }^{37}$ Cardiovascular complications and in-hospital mortality were reduced in patients at risk for POI who received alvimopan compared with matched controls. ${ }^{37}$ Similarly, in a study of patients undergoing radical cystectomy, the prolonged length of stay ( $>7$ days) was significantly lower for patients receiving alvimopan compared with that for those receiving placebo $(32.9 \%$ vs $51.5 \% ; P<0.01){ }^{34}$
Conflicting data, however, have been reported regarding the utility of alvimopan in patients undergoing surgery with intestinal anastomosis. In a recent small retrospective analysis of alvimopan $(n=55)$ and matched controls $(n=58)$, the authors found no significant difference in length of hospital stay (4.6 vs 4.8 days; $P=0.72$ ) or mean time to return to bowel function (68.5 vs $67.3 \mathrm{~h} ; P=0.83) .{ }^{38}$ This study demonstrated that patients treated with alvimopan incurred significantly greater charges for medical and surgical supplies, pathology and cytology services, operating room charges, and therapy charges $(P<0.05) .{ }^{38}$ However, these increases in costs were largely associated with surgical time and a shift in hospitalwide accelerated recovery efforts; they may also be due to differences in surgical complexity between groups. ${ }^{38}$ Nevertheless, this suggests that patient selection is important in deciding who should receive ERAS interventions, including PAMORAs, such as alvimopan.

\section{Alvimopan Safety}

In the majority of studies evaluating the safety and efficacy of alvimopan, the exclusion criteria prohibited preoperative use of opioids. ${ }^{28-31,33}$ As such, alvimopan is contraindicated in patients who are taking therapeutic doses of opioids for greater than 7 days before starting alvimopan. ${ }^{27}$ Further, the 


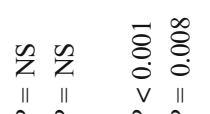

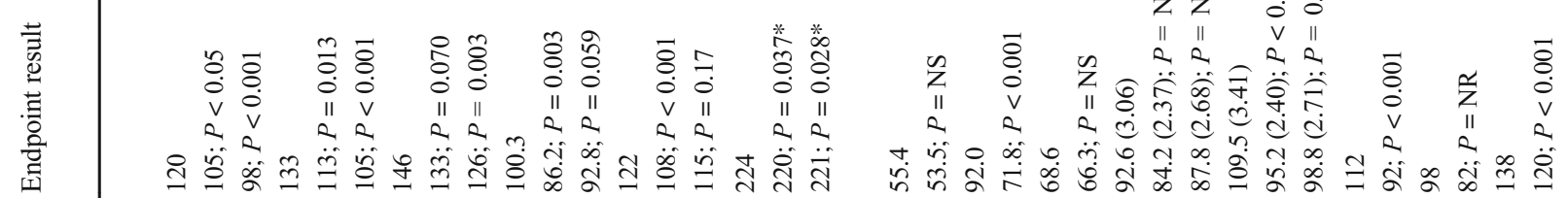

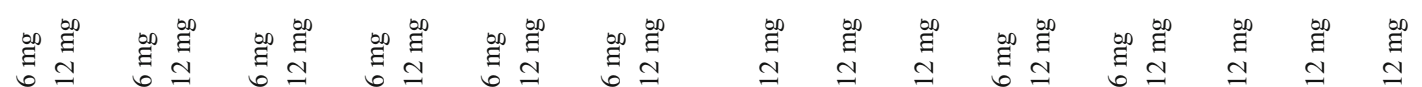

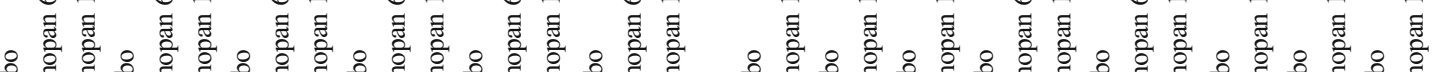

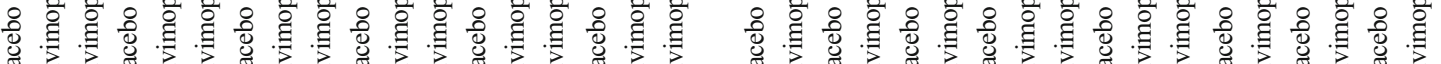

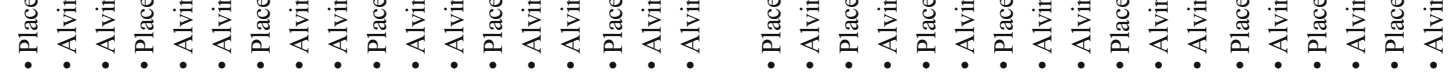 \\ 苛}

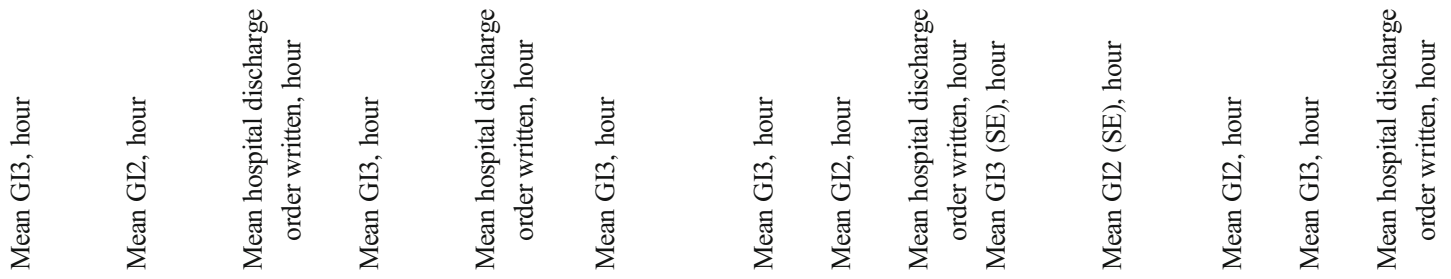

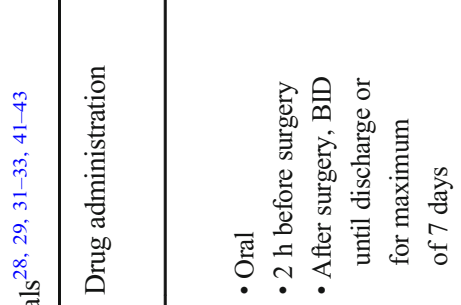

\section{Fene

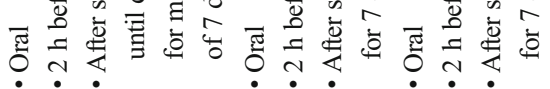

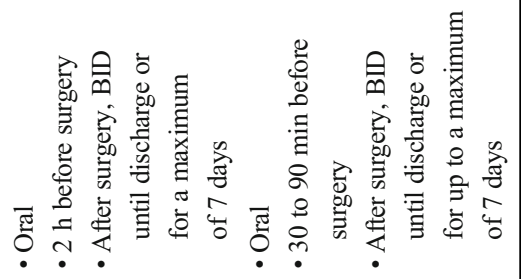

๖

용

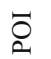

ำ

ర

ס

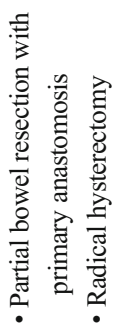

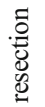
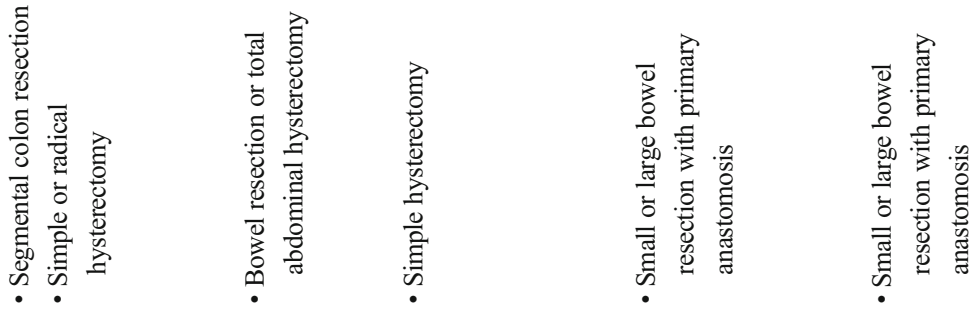

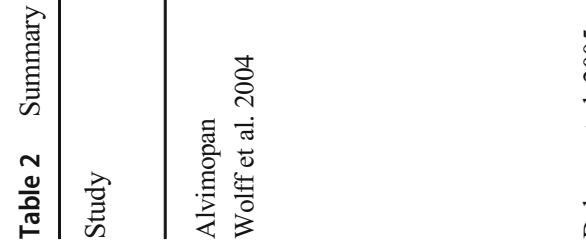
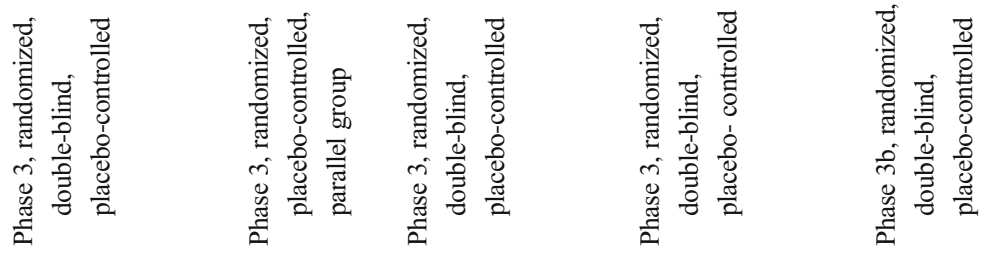

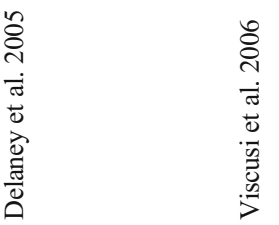

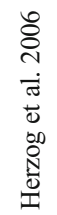

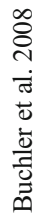

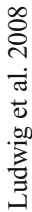




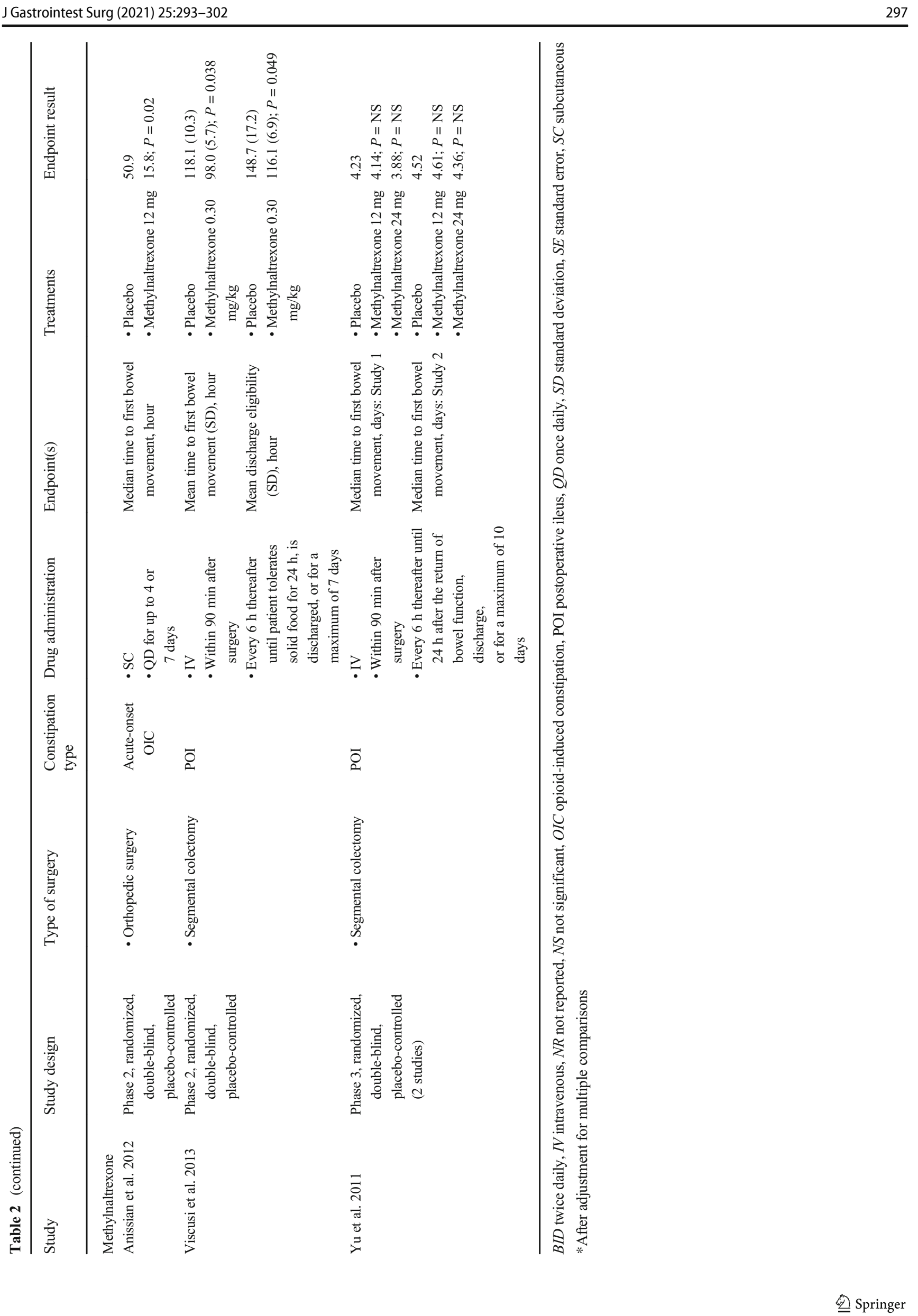


alvimopan label warns that recent exposure to opioids may increase the risk of abdominal pain, nausea, vomiting, and diarrhea since patients recently exposed to opioids may be more sensitive to the effects of PAMORAs. ${ }^{27}$

The duration of treatment with alvimopan is limited to short-term use in the hospital ( 15 doses) as noted in the boxed warning within the label. ${ }^{27}$ As such, an FDA risk evaluation and mitigation strategy is required to ensure that alvimopan use is restricted to the hospital setting. ${ }^{27}$ Secondly, the box warning also states that the incidence of MI was greater in patients receiving alvimopan compared with that in those receiving placebo in a 12-month study of patients treated with opioids for chronic noncancer pain. ${ }^{27}$ The increased incidence of MI and cardiovascular events with long-term treatment was not significantly different between treatment groups, but there was a numeric difference noted between groups. ${ }^{39} \mathrm{MI}$ and cardiovascular events were suffered by 7 (1.3\%) and 14 (2.6\%) patients who received alvimopan, respectively, compared with $0(0 \%)$ and $3(1.1 \%)$ patients who received placebo, respectively. All events occurred in patients who were at a high risk for or had established cardiovascular disease. ${ }^{39}$ While this was originally thought to be an overall function of the drug class, subsequent phase 3 and dedicated longterm safety studies of alvimopan in POI have failed to identify any increased risk for cardiovascular adverse events. ${ }^{36,37}$ Importantly, unlike the increased cardiovascular risks observed in the 12-month study, there was no increased risk of MI observed in short-term trials (up to 7 days) with alvimopan. $^{27}$

\section{Methylnaltrexone (Relistor ${ }^{\circledR}$ )}

Methylnaltrexone (formulated as a subcutaneous [SC] and oral dosage) is a PAMORA indicated for the treatment of OIC in adults with chronic noncancer pain, including patients with chronic pain related to prior cancer who are on a stable opioid dose. ${ }^{40} \mathrm{SC}$ methylnaltrexone is also indicated for the treatment of OIC in adults with advanced illness or active cancer who require an increase in opioid dose for palliative care (Table 1). ${ }^{40}$

For OIC in patients with chronic noncancer pain, methylnaltrexone is given as an SC injection of $12 \mathrm{mg}$ $\mathrm{SC}$ once daily or an oral 450-mg dose in the morning. For patients with advanced illness, the SC methylnaltrexone dosage is based on body weight and administered once every other day as needed. ${ }^{40}$ Patients who weigh 38 to $<62 \mathrm{~kg}$ should receive an $8-\mathrm{mg}$ dose, and patients who weigh 62 to $114 \mathrm{~kg}$ should receive a $12-\mathrm{mg}$ dose. Those who fall outside this weight range should receive a dose of $0.15 \mathrm{mg} / \mathrm{kg}$. ${ }^{40}$

While neither the injection nor the oral formulation of methylnaltrexone is indicated for POI or postoperative $\mathrm{OIC},{ }^{40}$ trials have been conducted in the postsurgical setting for both potential indications. ${ }^{41-43}$ These studies and their results are summarized in Table 2 and discussed below.

\section{Methylnaltrexone Efficacy and Safety}

A double-blind, randomized, parallel-group, placebocontrolled phase 2 study was performed to assess the safety and efficacy of SC methylnaltrexone in patients with acuteonset OIC after orthopedic surgery. ${ }^{41}$ In this small study, patients received once-daily medication, either methylnaltrexone $12 \mathrm{mg}(n=18)$ or placebo $(n=15)$, for up to 4 or 7 days. ${ }^{41}$ At 2 and $4 \mathrm{~h}$ postinjection, a significantly higher percentage of methylnaltrexone-treated patients achieved laxation (bowel movement) versus placebo ( $2 \mathrm{~h}, 33.3 \%$ vs $0 \%, P=0.021 ; 4$ h, $38.9 \%$ vs $6.7 \%, P=0.046$ ) (Table 2 ). ${ }^{41}$ Time to response was also significantly reduced with SC methylnaltrexone treatment versus placebo (median $15.8 \mathrm{~h}$ vs $50.9 \mathrm{~h}, P=$ 0.02 ). ${ }^{41}$ In addition, the rates of adverse events (AEs) were similar between the 2 groups, with $33.3 \%$ and $26.7 \%$ of patients in the SC methylnaltrexone and placebo groups, respectively, reporting at least 1 treatment-emergent AE. ${ }^{41}$ Most AEs reported were GI-related and considered to be possibly related to the study medication. ${ }^{41}$ No cardiac AEs were reported and no safety signals or pattern of concern was visualized by $\mathrm{ECG},{ }^{41}$ suggesting that methylnaltrexone exposure does not share the same cardiac risks and precautions as alvimopan. These results demonstrated that SC methylnaltrexone was effective in improving GI recovery and was generally welltolerated in patients with acute-onset OIC. ${ }^{41}$

Another phase 2, double-blind, randomized, controlled trial conducted in adults with POI after undergoing segmental colectomy showed that intravenous (IV) methylnaltrexone $(0.30 \mathrm{mg} / \mathrm{kg}$ in $50 \mathrm{~mL}$ of saline; $n=33)$, compared with placebo $(n=32)$, significantly decreased the time to first bowel movement. ${ }^{42}$ The study medication was administered within 90 min following the surgical procedure and was repeated every $6 \mathrm{~h}$ until solid food was tolerated for $24 \mathrm{~h}$; the patient was discharged, or the patient had received treatment for a maximum of 7 days. ${ }^{42}$ Compared with placebo, IV methylnaltrexone significantly accelerated the mean time to first bowel movement by $20 \mathrm{~h}(98.0 \mathrm{vs} 118.1 \mathrm{~h} ; P=0.038)$ and reduced the mean time to discharge eligibility by $33 \mathrm{~h}$ (116.1 vs $148.7 \mathrm{~h} ; P=0.049) .{ }^{42}$ In this study, methylnaltrexone was generally well-tolerated. In fact, GI AEs, including nausea, vomiting, and abdominal pain, were more frequently reported in the placebo group compared with that in the IV methylnaltrexone group. ${ }^{42}$ Notably, the incidence of POI was reduced 2-fold in IV methylnaltrexone-treated patients compared with that in those receiving placebo (6\% vs $16 \%){ }^{42}$

In a recent retrospective analysis of patients who underwent robotic-assisted radical cystectomy for bladder cancer, length of hospital stay, time to flatus and bowel movement, a composite of GI symptoms, episodes of severe pain, 
and daily opioid utilization were evaluated comparing SC methylnaltrexone ( $8 \mathrm{mg}$ in patients $<65 \mathrm{~kg}$ and $12 \mathrm{mg}$ in patients $\geq 65 \mathrm{~kg} ; n=29)$ with controls $(n=29) .{ }^{44}$ The median length of hospital stay was significantly reduced with methylnaltrexone treatment compared with the control group (4 vs 7 days, $P<0.01$ ), which contributed to a significant reduction in the total cost of hospital stay by more than $\$ 10,500$ USD per patient. The use of methylnaltrexone did not impact daily opioid usage or daily pain scores. In fact, there was a reduction in the number of severe pain episodes observed in methylnaltrexone-treated patients. Although there were no significant differences in the median time to flatus or bowel movement between patients who received methylnaltrexone compared with those patients in the control group, patients receiving methylnaltrexone had significantly fewer GI complications (methylnaltrexone cohort [10.3\%] vs no methylnaltrexone cohort [44.8\%], $P<0.01)$. The authors suggested that this finding may imply that the reduction of GI symptoms (bloating, distention, or discomfort) may be a factor in accelerated patient discharge.

\section{Potential Factors Contributing to Lack of Efficacy of Methylnaltrexone in the Treatment of POI in Phase 3 Trials}

The efficacy demonstrated in phase 2 trials could not be replicated in larger phase 3 trials. These phase 3 efficacy results were unexpected given the promising data from several phase 2 trials, but multiple factors may have contributed to the perceived lack of efficacy, some of which are reviewed here (Table 3).

The total amount of opioid administered to patients in the methylnaltrexone studies has not been reported. ${ }^{4}$ This is important as PAMORAs function to reduce POI by directly inhibiting opioid-mediated activation of $\mu$-opioid receptors in the GI tract. ${ }^{4}$ In the study inclusion criteria, patients using opioids prior to surgery were ineligible to participate in many of the alvimopan studies whereas these patients were not excluded from the methylnaltrexone studies. ${ }^{28-31,33}$ Ideally,

Table 3 Potential factors contributing to lack of efficacy of methylnaltrexone in the treatment of POI in phase 3 trials $4,41,43,46$

Total amount of opioid administered to patients is not reported and may not have been sufficient to activate $\mu$-opioid receptors

Multimodal treatment approaches and postoperative care may not have been matched between treatment groups

Endpoint selection may factor into observed lack of efficacy

Prior use of opioids may have saturated $\mu$-opioid receptors, leading to ineffective methylnaltrexone treatment

Dosing was inconsistent across studies; IV methylnaltrexone may not be the best route of administration for POI

Genetic polymorphisms and concomitant drug usage may produce interpatient variability treatment with a $\mu$-opioid receptor antagonist would start preoperatively in an opioid-naive patient, beginning prior to the exposure of any opioids during anesthesia. ${ }^{4}$ In the alvimopan studies, preoperative dosing was used instead of the postoperative dosing used in the methylnaltrexone POI studies. This is critical as high doses of opioids are generally given intraoperatively and may have saturated $\mu$-opioid receptors prior to treatment with methylnaltrexone. ${ }^{4}$ Furthermore, the doses used in the methylnaltrexone POI studies were the same as those used in the OIC studies. This is in contrast to the alvimopan analyses that used doses considerably higher in the POI studies compared with the OIC studies. ${ }^{32,45}$

Endpoint selection may also have contributed to variable efficacy results. In contrast to the composite endpoints used in the alvimopan trials (GI2 or GI3), single endpoints (i.e., time to first bowel movement or flatus) were assessed in the methylnaltrexone studies. ${ }^{4}$ Flatus, for example, when included in the GI3 composite endpoint, was found in the alvimopan studies to be a poor marker for GI recovery. ${ }^{29}$

Additionally, the phase 3 studies of methylnaltrexone utilized IV delivery, which introduced different dosing parameters than those used in the efficacious phase 2 OIC study. ${ }^{41,} 43$ Potential differences in the pharmacokinetics and pharmacodynamics between IV and SC dosing could have affected the efficacy of the drug. ${ }^{4}$ Finally, some opioids are P-glycoprotein substrates, requiring a functional P-glycoprotein for analgesic effect. ${ }^{46}$ Genetic polymorphisms and concomitant drug usage may produce interpatient variability in the expression of P-glycoprotein or other drug efflux transporters. ${ }^{46}$ This, in turn, may affect the absorption, distribution, or efficacy of PAMORAs. ${ }^{46}$

\section{Long-term Use and Effects on Survival in Methylnaltrexone Studies for OIC}

Although data on the use of methylnaltrexone in POI or postoperative OIC is limited, studies have shown safety and efficacy in trials up to 48 weeks in patients with noncancer pain ${ }^{47}$ and improved survival in cancer patients ${ }^{48}$ when used for OIC.

Long-term use of methylnaltrexone in patients with noncancer pain and OIC who received SC methylnaltrexone $12 \mathrm{mg}$ daily for 48 weeks was assessed in a phase 3 open-label trial. $^{47} \mathrm{~A}$ significant increase in mean weekly bowel movement rate change from baseline $(P<0.001)$ was observed through the entire 48 -week period. ${ }^{47}$ Similar to other studies of shorter duration, GI-related AEs were the most commonly reported AEs (i.e., abdominal pain $24.0 \%$, diarrhea $16.4 \%$, nausea $15.1 \%$ of patients). These rates are consistent with a long-term open-label study that found that GI-related AEs ranged from 15.5 to $19.3 \%{ }^{47}$ This study demonstrated that SC methylnaltrexone provided consistent long-term treatment for OIC without new safety concerns, suggesting that methylnaltrexone is safe and effective to use in the long term. ${ }^{47}$ 
A retrospective post hoc analysis of data pooled from 2 independent randomized, placebo-controlled clinical trials of SC methylnaltrexone in patients with advanced terminal cancer and OIC assessed whether treatment could influence survival. ${ }^{48}$ This analysis demonstrated that $\mathrm{SC}$ methylnaltrexone significantly increased the median overall survival compared with placebo (76 days, $95 \%$ confidence interval [CI] 43-109, vs 56 days, 95\% CI 43-69; $P=$ 0.033 ), indicating that methylnaltrexone may have an impact beyond relief of constipation, including a direct effect of methylnaltrexone on cellular targets related to the morphine receptor. ${ }^{48}$ Morphine antagonists have been shown to reduce tumor growth in several cancer in vivo models. ${ }^{49-52}$

\section{Other PAMORAs}

Naloxegol and naldemedine are two other PAMORAs indicated for the treatment of OIC in patients with chronic noncancer pain, but do not have an indication for POI. ${ }^{53,54}$ Although no studies have been conducted in POI treatment, a small study has been published in POI prevention. In an active comparator analysis, perioperative administration of naloxegol was compared with alvimopan among adult patients with bladder cancer who underwent a radical cystectomy. ${ }^{26}$ Among 130 patients, no differences were observed between those receiving naloxegol or alvimopan with respect to the development of POI or hospital length of stay. The authors postulated that although no other studies have been conducted with naloxegol, this active comparator study may help support the use of naloxegol as a less expensive alternative to alvimopan. To date, data evaluating the use of naldemedine for OIC in the surgical setting or for the treatment or prevention of POI have not been published.

\section{Future Direction}

Presently, with the exception of the small naloxegol versus alvimopan analysis, ${ }^{26}$ direct comparisons between PAMORAs are not possible because comparator studies between these agents have not been performed. Head-to-head studies are needed to make definitive conclusions as protocols and endpoints differ among the various studies.

The pathophysiology of POI is multifactorial and not exclusively related to opioid ligands. Therefore, a multimodal treatment strategy that takes into account inhibition of $\mu$ opioid receptors with PAMORAs, while including a variety of techniques or interventions with other mechanisms of action, may be needed. ${ }^{4}$ It is likely that the use of PAMORAs concurrently with these adjunct therapies will result in clinically meaningful acceleration of GI recovery after surgery ${ }^{4}$ beyond what can be achieved by any single intervention alone.
Differences in surgical approach (e.g., open, robot-assisted, or laparoscopic) and types of procedures (e.g., cystectomy vs colectomy) between studies may cause differences in rates of postoperative OIC and POI and the observed efficacy of PAMORAs. ${ }^{1,5-7}$ Furthermore, the alvimopan doses studied were those specific for use in POI, ${ }^{28-33}$ whereas in the postsurgical setting, the doses of methylnaltrexone studied were often those used in OIC studies. ${ }^{41,43}$ As such, further analysis into the appropriate dose of methylnaltrexone for POI may be necessary.

\section{Conclusions}

Pharmacologic options for the treatment or prevention of POI are limited. Currently, alvimopan is the only PAMORA approved for POI that improves GI recovery after surgery and reduces the length of hospital of stay. Although methylnaltrexone is not indicated for POI, studies have shown that it effectively reverses unwanted opioid-induced GI side effects while preserving CNS-mediated analgesia in specific surgical settings. Further studies with methylnaltrexone are warranted to determine its utility in prevention and/or treatment of POI. Given the inconsistencies observed between current studies, future trial designs should be carefully considered in order to evaluate efficacy.

Acknowledgments Technical editorial and medical writing assistance were provided under the direction of the authors by Dana A. Franznick, PharmD, of Echelon Brand Communications, LLC, an OPEN Health company, Parsippany, NJ, USA. Funding for this assistance was provided by Salix Pharmaceuticals, a division of Bausch Health US, LLC, Bridgewater, NJ, USA.

\section{Compliance with Ethical Standards}

Conflict of Interest Dr. Chamie has received compensation for consulting from UroGen Pharma.

Dr. Golla has nothing to disclose.

Dr. Lenis has nothing to disclose.

Dr. Lec has nothing to disclose.

Dr. Rahman has nothing to disclose.

Dr. Viscusi has received compensation for consulting from AcelRx, Avenue, Cara, Concentric, Heron, Innocoll, Mallinckrodt, Merck, Neumentum, Pacira, Pfizer, Recro, Salix, and Trevena and has received grants for Pacira and Durect.

Open Access This article is licensed under a Creative Commons Attribution 4.0 International License, which permits use, sharing, adaptation, distribution and reproduction in any medium or format, as long as you give appropriate credit to the original author(s) and the source, provide a link to the Creative Commons licence, and indicate if changes were made. The images or other third party material in this article are included in the article's Creative Commons licence, unless indicated otherwise in a credit line to the material. If material is not included in the article's Creative Commons licence and your intended use is not permitted by statutory regulation or exceeds the permitted use, you will need to obtain 
permission directly from the copyright holder. To view a copy of this licence, visit http://creativecommons.org/licenses/by/4.0/.

\section{References}

1. Venara A, Neunlist M, Slim K, et al. Postoperative ileus: pathophysiology, incidence, and prevention. J Visc Surg. 2016;153:439446.

2. Barletta JF, Asgeirsson T, Senagore AJ. Influence of intravenous opioid dose on postoperative ileus. Ann Pharmacother. 2011;45: 916-923.

3. Bragg D, El-Sharkawy AM, Psaltis E, Maxwell-Armstrong CA, Lobo DN. Postoperative ileus: recent developments in pathophysiology and management. Clin Nutr. 2015;34:367-376.

4. Kraft MD. Methylnaltrexone, a new peripherally acting mu-opioid receptor antagonist being evaluated for the treatment of postoperative ileus. Expert Opin Investig Drugs. 2008;17:1365-1377.

5. Gan TJ, Robinson SB, Oderda GM, Scranton R, Pepin J, Ramamoorthy S. Impact of postsurgical opioid use and ileus on economic outcomes in gastrointestinal surgeries. Curr Med Res Opin. 2015;31:677-686.

6. Delaney CP, Chang E, Senagore AJ, Broder M. Clinical outcomes and resource utilization associated with laparoscopic and open colectomy using a large national database. Ann Surg. 2008;247: 819-824.

7. Delaney CP, Marcello PW, Sonoda T, Wise P, Bauer J, Techner L. Gastrointestinal recovery after laparoscopic colectomy: results of a prospective, observational, multicenter study. Surg Endosc. 2010;24:653-661.

8. The FO, Bennink RJ, Ankum WM, et al. Intestinal handlinginduced mast cell activation and inflammation in human postoperative ileus. Gut. 2008;57:33-40.

9. Senagore AJ. Pathogenesis and clinical and economic consequences of postoperative ileus. Am J Health Syst Pharm. 2007;64(suppl 13):S3-S7.

10. Murphy MM, Tevis SE, Kennedy GD. Independent risk factors for prolonged postoperative ileus development. J Surg Res. 2016;201: 279-285.

11. Augestad KM, Delaney CP. Postoperative ileus: impact of pharmacological treatment, laparoscopic surgery and enhanced recovery pathways. World J Gastroenterol. 2010;16:2067-2074.

12. Guay J, Nishimori M, Kopp S. Epidural local anaesthetics versus opioid-based analgesic regimens for postoperative gastrointestinal paralysis, vomiting and pain after abdominal surgery. Cochrane Database Syst Rev. 2016;7:CD001893.

13. Herroeder S, Pecher S, Schonherr ME, et al. Systemic lidocaine shortens length of hospital stay after colorectal surgery: a doubleblinded, randomized, placebo-controlled trial. Ann Surg. 2007;246: 192-200.

14. Chen JY, Ko TL, Wen YR, et al. Opioid-sparing effects of ketorolac and its correlation with the recovery of postoperative bowel function in colorectal surgery patients: a prospective randomized double-blinded study. Clin J Pain. 2009;25:485-489.

15. Lohsiriwat V. Opioid-sparing effect of selective cyclooxygenase-2 inhibitors on surgical outcomes after open colorectal surgery within an enhanced recovery after surgery protocol. World J Gastrointest Oncol. 2016;8:543-549.

16. Camilleri M, Lembo A, Katzka DA. Opioids in gastroenterology: Treating adverse effects and creating therapeutic benefits. Clin Gastroenterol Hepatol. 2017;15:1338-1349.
17. Viscusi ER, Gan TJ, Leslie JB, et al. Peripherally acting mu-opioid receptor antagonists and postoperative ileus: mechanisms of action and clinical applicability. Anesth Analg. 2009;108:1811-1822.

18. Leppert W. Emerging therapies for patients with symptoms of opioid-induced bowel dysfunction. Drug Des Devel Ther. 2015;9: 2215-2231.

19. Schwenk ES, Grant AE, Torjman MC, McNulty SE, Baratta JL, Viscusi ER. The efficacy of peripheral opioid antagonists in opioidinduced constipation and postoperative ileus: a systematic review of the literature. Reg Anesth Pain Med. 2017;42:767-777.

20. Liu M, Wittbrodt E. Low-dose oral naloxone reverses opioidinduced constipation and analgesia. J Pain Symptom Manage. 2002;23:48-53.

21. Yuan CS, Foss JF. Antagonism of gastrointestinal opioid effects. Reg Anesth Pain Med. 2000;25:639-642.

22. Skolnick P. On the front lines of the opioid epidemic: rescue by naloxone. Eur J Pharmacol. 2018;835:147-153.

23. Becker G, Blum HE. Novel opioid antagonists for opioid-induced bowel dysfunction and postoperative ileus. Lancet. 2009;373: 1198-1206.

24. Holzer P. New approaches to the treatment of opioid-induced constipation. Eur Rev Med Pharmacol Sci. 2008;12 (suppl 1):119-127.

25. Leppert W, Woron J. The role of naloxegol in the management of opioid-induced bowel dysfunction. Therap Adv Gastroenterol. 2016;9:736-746.

26. Goodstein $\mathrm{T}$, Launer $\mathrm{B}$, White $\mathrm{S}$, et al. A retrospective study of patients undergoing radical cystectomy and receiving perioperative naloxegol or alvimopan: comparison of length of stay. $J$ Surg (N Y N Y). 2018;6:129-134.

27. Entereg [package insert]. Whitehouse Station, NJ: Merck Sharp \& Dohme Corp; 2015.

28. Ludwig K, Enker WE, Delaney CP, et al. Gastrointestinal tract recovery in patients undergoing bowel resection: results of a randomized trial of alvimopan and placebo with a standardized accelerated postoperative care pathway. Arch Surg. 2008;143:10981105.

29. Buchler MW, Seiler CM, Monson JR, et al. Clinical trial: alvimopan for the management of post-operative ileus after abdominal surgery: results of an international randomized, double-blind, multicentre, placebo-controlled clinical study. Aliment Pharmacol Ther. 2008;28:312-325.

30. Viscusi ER, Goldstein S, Witkowski T, et al. Alvimopan, a peripherally acting mu-opioid receptor antagonist, compared with placebo in postoperative ileus after major abdominal surgery: results of a randomized, double-blind, controlled study. Surg Endosc. 2006;20: 64-70.

31. Delaney CP, Weese JL, Hyman NH, et al. Phase III trial of alvimopan, a novel, peripherally acting, mu opioid antagonist, for postoperative ileus after major abdominal surgery. Dis Colon Rectum. 2005;48:1114-1125.

32. Wolff BG, Michelassi F, Gerkin TM, et al. Alvimopan, a novel, peripherally acting mu opioid antagonist: results of a multicenter, randomized, double-blind, placebo-controlled, phase III trial of major abdominal surgery and postoperative ileus. Ann Surg. 2004;240: $728-734$.

33. Herzog TJ, Coleman RL, Guerrieri JP, Jr., et al. A double-blind, randomized, placebo-controlled phase III study of the safety of alvimopan in patients who undergo simple total abdominal hysterectomy. Am J Obstet Gynecol. 2006;195:445-453.

34. Lee CT, Chang SS, Kamat AM, et al. Alvimopan accelerates gastrointestinal recovery after radical cystectomy: a multicenter randomized placebo-controlled trial. Eur Urol. 2014;66:265-272.

35. Delaney CP, Senagore AJ, Viscusi ER, et al. Postoperative upper and lower gastrointestinal recovery and gastrointestinal morbidity in patients undergoing bowel resection: pooled analysis of placebo 
data from 3 randomized controlled trials. Am J Surg. 2006;191: 315-319.

36. Steele SR, Brady JT, Cao Z, et al. Evaluation of healthcare use and clinical outcomes of alvimopan in patients undergoing bowel resection: a propensity score-matched analysis. Dis Colon Rectum. 2018;61:1418-1425.

37. Al-Mazrou AM, Baser O, Kiran RP. Alvimopan, regardless of ileus risk, significantly impacts ileus, length of stay, and readmission after intestinal surgery. J Gastrointest Surg. 2018;22:2104-2116.

38. Nemeth ZH, Bogdanovski DA, Paglinco SR, Barratt-Stopper P, Rolandelli RH. Cost and efficacy examination of alvimopan for the prevention of postoperative ileus. J Investig Med. 2017;65: 949-952.

39. Brenner DM, Chey WD. An evidence-based review of novel and emerging therapies for constipation in patients taking opioid analgesics. Am J Gastroenterol Suppl. 2014;2:38-46.

40. Relistor [package insert]. Bridgewater, NJ: Salix Pharmaceuticals; 2018.

41. Anissian L, Schwartz HW, Vincent K, et al. Subcutaneous methylnaltrexone for treatment of acute opioid-induced constipation: phase 2 study in rehabilitation after orthopedic surgery. $J$ Hosp Med. 2012;7:67-72.

42. Viscusi ER, Rathmell JP, Fichera A, et al. Randomized placebocontrolled study of intravenous methylnaltrexone in postoperative ileus. J Drug Assess. 2013;2:127-134.

43. Yu CS, Chun HK, Stambler N, et al. Safety and efficacy of methylnaltrexone in shortening the duration of postoperative ileus following segmental colectomy: results of two randomized, placebo-controlled phase 3 trials. Dis Colon Rectum. 2011;54: $570-578$.

44. Lenis AT, Golla V, Lec PM, et al. The association between Nmethylnaltrexone, a peripherally acting mu-opioid receptor antagonist, and clinical outcomes in patients undergoing robotic-assisted radical cystectomy. World J Urol. 2020; https://doi.org/10.1007/ s00345-020-03117-y

45. Webster L, Jansen JP, Peppin J, et al. Alvimopan, a peripherally acting mu-opioid receptor (PAM-OR) antagonist for the treatment of opioid-induced bowel dysfunction: results from a randomized, double-blind, placebo-controlled, dose-finding study in subjects taking opioids for chronic non-cancer pain. Pain. 2008;137:428 440.

46. Rollason V, Samer C, Piguet V, Dayer P, Desmeules J. Pharmacogenetics of analgesics: toward the individualization of prescription. Pharmacogenomics. 2008;9:905-933.

47. Webster LR, Michna E, Khan A, Israel RJ, Harper JR. Long-term safety and efficacy of subcutaneous methylnaltrexone in patients with opioid-induced constipation and chronic noncancer pain: a phase 3, open-label trial. Pain Med. 2017;18:1496-1504.

48. Janku F, Johnson LK, Karp DD, Atkins JT, Singleton PA, Moss J. Treatment with methylnaltrexone is associated with increased survival in patients with advanced cancer. Ann Oncol. 2016;27:20322038.

49. McLaughlin PJ, Stucki JK, Zagon IS. Modulation of the opioid growth factor ([Met(5)]-enkephalin)-opioid growth factor receptor axis: novel therapies for squamous cell carcinoma of the head and neck. Head Neck. 2012;34:513-519.

50. Boehncke S, Hardt K, Schadendorf D, Henschler R, Boehncke WH, Duthey B. Endogenous mu-opioid peptides modulate immune response towards malignant melanoma. Exp Dermatol. 2011;20: 24-28.

51. Nguyen J, Luk K, Vang D, et al. Morphine stimulates cancer progression and mast cell activation and impairs survival in transgenic mice with breast cancer. Br J Anaesth. 2014;113 (suppl 1):i4-i13.

52. Mathew B, Lennon FE, Siegler J, et al. The novel role of the mu opioid receptor in lung cancer progression: a laboratory investigation. Anesth Analg. 2011;112:558-567.

53. Movantik [package insert]. Wilmington, DE: AstraZeneca Pharmaceuticals; 2018.

54. Symproic [package insert]. Florham Park, NJ: Shionogi Inc.; 2018.

Publisher's Note Springer Nature remains neutral with regard to jurisdictional claims in published maps and institutional affiliations. 